\title{
The blockade of cyclooxygenases- 1 and -2 reduces the effects of hypoxia on endothelial cells
}

\section{M.A. Gloria ${ }^{1}$, \\ M.A. Cenedeze ${ }^{1}$, \\ A. Pacheco-Silva ${ }^{1}$ and N.O.S. Câmara ${ }^{1,2}$}

\author{
${ }^{1}$ Laboratório de Imunologia Clínica e Experimental, Divisão de Nefrologia, \\ Universidade Federal de São Paulo, Hospital do Rim e Hipertensão, \\ Fundação Oswaldo Ramos, São Paulo, SP, Brasil \\ ${ }^{2}$ Laboratório de Imunobiologia de Transplantes, Departamento de Imunologia, \\ Instituto de Ciências Biomédicas IV, Universidade de São Paulo, São Paulo, SP, Brasil
}

\author{
Correspondence \\ N.O.S. Câmara \\ Laboratório de Imunologia Clínica \\ e Experimental \\ Divisão de Nefrologia, UNIFESP \\ Rua Botucatu, 740 \\ 04023-900 São Paulo, SP \\ Brasil \\ Fax: +55-11-5573-9652 \\ E-mail: niels@nefro.epm.br \\ Research supported by CAPES and \\ FAPESP (Nos. 04/08311-6 and \\ 04/13826-5).
}

Received August 19, 2005

Accepted May 31, 2006

\begin{abstract}
Hypoxia activates endothelial cells by the action of reactive oxygen species generated in part by cyclooxygenases (COX) production enhancing leukocyte transmigration. We investigated the effect of specific COX inhibition on the function of endothelial cells exposed to hypoxia. Mouse immortalized endothelial cells were subjected to $30 \mathrm{~min}$ of oxygen deprivation by gas exchange. Acridine orange/ ethidium bromide dyes and lactate dehydrogenase activity were used to monitor cell viability. The mRNA of COX-1 and -2 was amplified and semi-quantified before and after hypoxia in cells treated or not with indomethacin, a non-selective COX inhibitor. Expression of RANTES (regulated upon activation, normal $\mathrm{T}$ cell expressed and secreted) protein and the protective role of heme oxygenase-1 (HO-1) were also investigated by PCR. Gas exchange decreased partial oxygen pressure $\left(\mathrm{PaO}_{2}\right)$ by $45.12 \pm 5.85 \%$ (from $162 \pm 10$ to $73 \pm 7.4$ $\mathrm{mmHg}$ ). Thirty minutes of hypoxia decreased cell viability and enhanced lactate dehydrogenase levels compared to control $(73.1 \pm 2.7$ vs $91.2 \pm 0.9 \%, \mathrm{P}<0.02 ; 35.96 \pm 11.64$ vs $22.19 \pm 9.65 \%, \mathrm{P}=0.002$, respectively). COX-2 and HO-1 mRNA were up-regulated after hypoxia. Indomethacin $(300 \mu \mathrm{M})$ decreased COX-2, HO-1, hypoxiainducible factor- $1 \alpha$ and RANTES mRNA and increased cell viability after hypoxia. We conclude that blockade of COX up-regulation can ameliorate endothelial injury, resulting in reduced production of chemokines.
\end{abstract}

\section{Introduction}

Acute renal failure, a clinical feature of ischemia and reperfusion injury (IRI), remains a major cause of morbidity and mortality in hospitalized patients (1). In the transplantation area, IRI is closely related to early and long-term graft outcomes. Indeed, grafts
Key words

- Endothelial cell

- Hypoxia

- Indomethacin

- Cyclooxygenase

- Heme oxygenase 1

................. from recipients with delayed graft function are more associated with chronic allograft nephropathy and consequently with a reduced survival rate $(2,3)$.

The cellular mechanisms involved in IRI include ATP depletion, impaired calcium regulation, generation of reactive oxygen species (ROS), and the production of pro- 
inflammatory cytokines/chemokines. All these mediators ultimately contribute to activation of endothelial cells $(4,5)$. Endothelial cell activation is associated with pro-coagulant and pro-inflammatory phenotypes. The up-regulation of class II molecules of the major histocompatibility complex, together with secretion of chemokines, promotes leukocyte adhesion and further transmigration of leukocytes through the endothelial barrier into the tissue. Regulated upon activation, normal T cell expressed and secreted (RANTES) protein is a key molecule involved in these events which is secreted by endothelial cells and activated leukocytes $(6,7)$.

Cyclooxygenase (COX) is the key enzyme implicated in the generation of prostaglandins from arachidonic acid (8), a process that promotes the generation of ROS (9). Both isoforms, COX-1 and COX-2, participate in the endothelial cell activation that follows IRI $(9,10)$. We have shown that COX blockade in the murine model of IRI leads to better organ function and preserves the parenchymal architecture $(11,12)$. The mechanisms underlying this beneficial effect are not completely understood.

It has become apparent that the balance between the injury factors and the tissue responses that follow the initial damage is a determinant of organ outcome. The tissue can protect itself from injury by up-regulating a group of genes with anti-apoptotic and anti-inflammatory properties, intended to promote and maintain the physiological functions of the organs. Heme oxygenase-1 (HO1 ) is one of the recently described protective genes. The mechanisms underlying its role are not clear, but probably rely on the ability of this gene to protect endothelial cells from undergoing apoptosis, to inhibit the proinflammatory phenotype of activated monocytes/macrophages, to promote vasodilatation, to suppress platelet activation, and to block smooth cell proliferation. These effects occur via generation of carbon monoxide, biliverdin and free iron, the end prod- ucts of heme metabolism catalyzed by HO-1 (reviewed in Ref. 13). The enhanced HO-1 expression observed during hypoxia is due to activation of the transcription factor, hypoxia-inducible factor (HIF)- $1 \alpha$. HIF- $1 \alpha$ is a heterodimeric peptide involved not only in the sensing, but also in the adapting of cells to changes in $\mathrm{O}_{2}$ levels. It is well established that HIF-1 expression and activation correlate with tumor progression, cell apoptosis, resistance to cancer treatment, and angiogenesis (14-16).

On the basis of these considerations, we hypothesize that the beneficial effects observed with COX blockade in ischemic organ injuries might be mediated in part by the amelioration of the response of endothelial cells to hypoxia. We addressed this question by investigating the effect of specific COX blockade (non-selective inhibition of COX1 and COX-2) in an in vitro model of gaseous hypoxia. We anticipated that pre-treatment with indomethacin would promote better endothelial cell viability and down-regulation of COX-2 and RANTES messenger RNA (mRNA) in the presence of hypoxia. In addition, COX inhibition was also associated with a reduced expression of HO-1 and HIF-1 $\alpha$ gene transcripts under hypoxic conditions.

\section{Material and Methods}

\section{Cells}

Mouse immortalized endothelial cells were purchased from the American Type of Culture Collection (ATCC, CRL-2167, Manassas, VA, USA) and cultivated in Dulbecco's modified Eagle's medium (Gibco, Carlsbald, CA, USA) supplemented with 5\% fetal bovine serum (Cultilab, Campinas, SP, Brazil), HEPES, and penicillin/streptomycin. All cultures were maintained in $25-\mathrm{cm}^{2}$ polystyrene bottles in an incubator at $37^{\circ} \mathrm{C}$ and humidified with a gaseous mixture of 95\% air and 5\% carbon dioxide. 


\section{Gas hypoxia}

Each culture bottle was capped with a silicone cork and sealed with paraffin. We used two $30 \times 7-\mathrm{mm}$ needles to transfix the cork to provide an access to infuse the gaseous mixture containing $95 \%$ nitrogen and $5 \%$ carbon dioxide. Three to 4 liters per minute of this gaseous mixture were infused for $30 \mathrm{~min}$, reducing the partial oxygen pressure $\left(\mathrm{PaO}_{2}, 162 \pm 10 \mathrm{mmHg}\right)$ in the culture medium (17). $\mathrm{PaO}_{2}$ was measured with a potentiometric electrode in a blood gas analyzer. Cells were then harvested for the experiments.

\section{Drugs}

Indomethacin (Sigma, St. Louis, MO, USA) was used at two different concentrations, 100 and $300 \mu \mathrm{M}$, for $72 \mathrm{~h}$ prior to the gaseous hypoxia. Controls included cells not treated with indomethacin or treated with the vehicle (DMSO, 10 and $30 \mu \mathrm{L}$ ), subjected or not to hypoxia. The cells were studied immediately after hypoxia, with no reperfusion.

\section{Protocol of cell injury}

Cell viability was determined by the exclusion method using two fluorescent dyes. After trypsinization the cells were resuspended in $1 \mathrm{~mL}$ PBS. A solution of acridine orange $(100 \mu \mathrm{g} / \mathrm{mL})$ and ethidium bromide $(100 \mu \mathrm{g} / \mathrm{mL})$ was added to the $10-\mu \mathrm{L}$ cell sample. Ethidium bromide and acridine orange excite orange and green fluorescence, respectively, when they are intermingled within the DNA. Ethidium bromide is eliminated when the plasma membrane is intact and therefore only acridine orange crosses the membrane, leading to green fluorescence. A brilliant orange coloration is observed when both ethidium bromide and acridine orange are absorbed by the cells (17). Approximately 150 to 200 cells were counted and considered to be viable when they were stained green and nonviable when they were stained orange. Results are reported as percent viable cells.

Cell viability was also measured by lactate dehydrogenase ( $\mathrm{LDH})$ leakage through the membrane into the medium. This assay, which strongly correlates with the number of lysed cells, was based on the reduction of nicotinamide-adenine dinucleotide (NAD) to NADH by LDH (18). LDH activity in the supernatant and in the cell homogenate was determined by measuring absorbance at 340 nm. Cytotoxicity was reported as percent $\mathrm{LDH}$ released, corresponding to the ratio between LDH activity in the supernatant and total LDH activity. Throughout the entire reading, the samples were maintained under shaking and at a constant temperature of $25^{\circ} \mathrm{C}$.

\section{mRNA expression}

RNA was extracted from endothelial cells exposed or not to gaseous hypoxia, and pretreated or not with indomethacin, using TRIREAGENT $^{\text {TM }}$ (Sigma), according to the manufacturer's protocol. RNA concentration was quantified with a spectrophotometer. Samples with an $\mathrm{A}_{260} / \mathrm{A}_{280}$ ratio above 1.7 were considered to be free of DNA and proteins. mRNA was reverse transcribed into complementary DNA using expand reverse polymerase (Boehringer Mannheim, East Sussex, UK). The mRNA of COX-1, COX2 , HO-1, HIF-1 $\alpha$, RANTES, and $\beta$-actin was amplified using specific primer sequences: COX-1 280 bp, sense: 5' GGT GGA GGT AGG AAC TTT GAC 3', anti-sense: 5' GAG CCC CCA TCT CTA TCA TAC 3'; COX-2: 448 bp, sense: 5' CAT TGA AGA CCA GGA GTA 3', anti-sense: 5' CCA GTA TTG AGG AGA ACA 3'; HO-1: 102 bp, sense: 5' TGA CAC CTG AGG TCA AGC ACA 3', anti-sense: 5' GTT CGT CTG TCA GCA CCT G 3'; HIF-1 1 96 bp, sense: 5' ATT GCA GCA ACC AGG TGA CTG 3', 
anti-sense: 5' GCA GCT TGC ATG CTA ATT CGG 3'; RANTES: 205 bp, sense: 5' CCC ATA TGG CTC GGA CAC CA 3', anti-sense: 5' CTA GCT CAT CTC CAA ATA GTT GAT 3', and B-actin: 375 bp, sense: 5' CGT GAC ATT AAG GAG AAG CTG TGC 3', anti-sense: 5' CTC AGG AGG AGC AAT GAT CTT GAT 3'. PCR was performed with $5 \mu \mathrm{L}$ cDNA in a $25-\mu \mathrm{L}$ reaction volume using PCR Master Mix ${ }^{\mathrm{TM}}$ (Promega, Southampton, UK). The PCR conditions consisted of 35 cycles of denaturation at $95^{\circ} \mathrm{C}(1 \mathrm{~min})$, annealing at $55^{\circ} \mathrm{C}$ for 1.5 min and extension at $72^{\circ} \mathrm{C}$ for $2 \mathrm{~min}$, followed by a final incubation of $72^{\circ} \mathrm{C}$ for 10 min. These conditions were applied to all primers. PCR products were run on $1.5 \%$ agarose gel and stained with a fluorescent dye (Syber Green I, Molecular Probes, Carlsbald, CA, USA). The gels were scanned to estimate relative band intensity using a Storm scanner and Image Quant 4.0 software (Molecular Dynamics, Sunnyvale, CA, USA). Semi-quantitative RNA estimation was carried out with $B$-actin as an internal control. The results are reported as the ratio of arbitrary units of the band densities of the gene and of the internal control (B-actin).

\section{Statistical analysis}

Data are reported as means $\pm \mathrm{SD}$ or as percent increase unless otherwise stated. PCR products were analyzed by densitometry and

Figure 1. COX-1/B-actin mRNA ratios in control endothelial cells, in endothelial cells subjected to hypoxia and in cells pre-treated with 100 and $300 \mu \mathrm{M}$ indomethacin and subjected to hypoxia. Data are reported as the median of 14 independent experiments. COX $=$ cyclooxygenase. ${ }^{*} \mathrm{P}<$ 0.05 compared to hypoxia (no indomethacin) (Mann-Whitney U-test). semi-quantified, and the results are shown in histograms. Each gene transcript was normalized to $B$-actin mRNA values and was reported as median and ranges. Percent increase and a decrease in mRNA expression were calculated according to basal expression used as a reference level. Parametric and non-parametric tests were used for comparison among groups, with the level of significance set at $\mathrm{P}<0.05$.

\section{Results}

\section{Cell injury protocol}

Gas insufflation induced a reduction of $45.12 \pm 5.85 \%$ in $\mathrm{PaO}_{2}$. Endothelial cells subjected to gaseous hypoxia showed a higher level of LDH release $(35.96 \pm 11.64$ vs $22.19 \pm 9.65 \%, \mathrm{P}=0.002)$ and low viability (percentage of viable cells: $73.1 \pm 2.73$ vs $91.2 \pm 0.95 \%, \mathrm{P}<0.05)$ compared to those that remained in a non-hypoxic state. Under normoxic conditions, vehicle and indomethacin treatments alone did not alter cell viability or LDH release (viability: 88.9 \pm 1.8 and $92.5 \pm 5.3 \%$, respectively; $\mathrm{LDH}$ release: $16.4 \pm 3.4$ and $18.7 \pm 2.8 \%$, respectively).

\section{Gene transcript analyses}

Immortalized endothelial cells expressed COX-2 mRNA under basal conditions, although at a lower level compared to COX-1 mRNA expression, $0.38(0.179-0.95)$ and 0.67 (0.06-1.14), respectively. After hypoxia, we observed mRNA in the same proportion of up-regulation of both COX isoforms (27 and 29\%) compared to pre-hypoxic levels (COX-2: 0.53, 0.29-0.80; COX-1: 0.86, $0.282-1.13)$. Indomethacin was then added to the culture at two different concentrations; $100 \mu \mathrm{M}$ indomethacin inhibited COX1 and COX-2 mRNA by 40 and 29\%, respectively, whereas a higher concentration of $300 \mu \mathrm{M}$ caused 100 and $99 \%$ inhibition, 
respectively. The arbitrary units of mRNA COX-1 and COX-2 normalized to B-actin mRNA levels were shown in Figures 1 and 2.

\section{Effect of COX inhibition on endothelial cell function}

Once we had determined the best concentration to use associated with COX mRNA inhibition, we evaluated its effect on cell integrity. Prior treatment with $300 \mu \mathrm{M}$ indomethacin improved the viability of cells subjected to the hypoxic insult compared to those treated with vehicle (percentage of viable cells: $87.8 \pm 2$ vs $73.1 \pm 2.73 \%, \mathrm{P}=$ $0.015)$. Thus, the viability of vehicle-treated cells subjected to hypoxia did not increase $(76.7 \pm 3.8 \%)$.

Most striking, indomethacin $(300 \mu \mathrm{M})$ inhibited the expression of RANTES mRNA that was up-regulated after hypoxia. Indomethacin-treated hypoxic endothelial cells showed a lower chemokine expression than cells pre-treated with vehicle (Figure 3).

The immortalized endothelial cells did not express HO-1 mRNA at the basal level. However, after $30 \mathrm{~min}$ of gaseous hypoxia, HO-1 mRNA was highly up-regulated, showing the pattern of a stress-inducible gene. Indomethacin pre-treatment did not induce HO-1 mRNA expression in those cells that remained in a non-hypoxic state (data not shown). Therefore, when it was added to hypoxia-stressed endothelial cells, indomethacin significantly down-regulated $\mathrm{HO}-1$ mRNA expression, mainly at a higher concentration (Figure 4A). The down-regulation of the HO-1 transcript was simultaneous to the decrease in COX-2 mRNA. Since hypoxia-induced HO-1 expression is mainly regulated by HIF- $1 \alpha$, we then investigated its mRNA under similar conditions. Similar to what was just described, HIF- $1 \alpha$ was markedly up-regulated after hypoxia and down-regulated by prior indomethacin treatment, namely at a concentration of 300 $\mu \mathrm{M}$ (Figure 4, panel B).

\section{Discussion}

Endothelial cells play a central role in the inflammatory response to ischemic injury. They can be either a target of the aggression

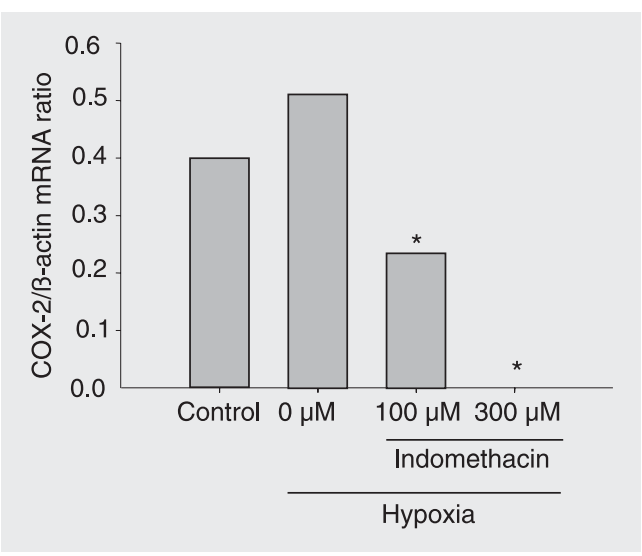

Figure 2. COX-2/B-actin mRNA in control endothelial cells, in endothelial cells subjected to hypoxia and in cells pre-treated with 100 and $300 \mu \mathrm{M}$ indomethacin and subjected to hypoxia. COX = cyclooxygenase. Data are reported as the median of 14 independent experiments. ${ }^{*} \mathrm{P}<$ 0.05 compared to hypoxia (no indomethacin) (Mann-Whitney U-test).

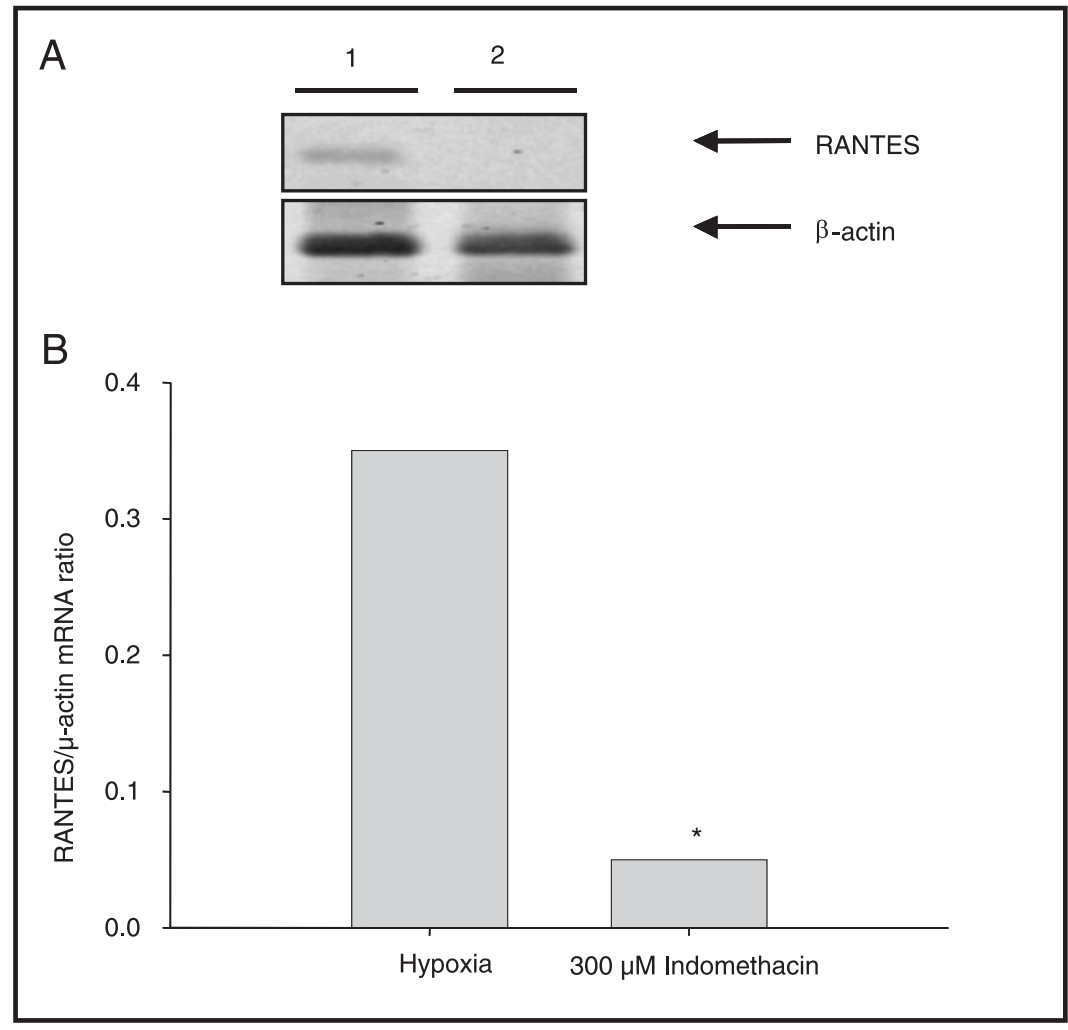

Figure 3. Typical gel of RANTES and B-actin mRNA expressed by endothelial cells treated with $300 \mu \mathrm{M}$ indomethacin or vehicle and subjected to hypoxia (panel A) and the corresponding values obtained by gel densitometry (panel B). RANTES and B-actin amplified a fragment of 205 and $375 \mathrm{bp}$, respectively. Data are reported as the median of 4 independent experiments. RANTES $=$ regulated upon activation, normal T cell expressed and secreted molecule. $\mathrm{P}<0.05$ for indomethacin-treated cells vs vehicle-treated cells (Mann-Whitney U-test). 
or a mediator of an active protective process that intends to limit the hypoxic damage. Endothelial cell activation leads to pro-inflammatory cytokine and chemokine production, which promotes activation of leu-

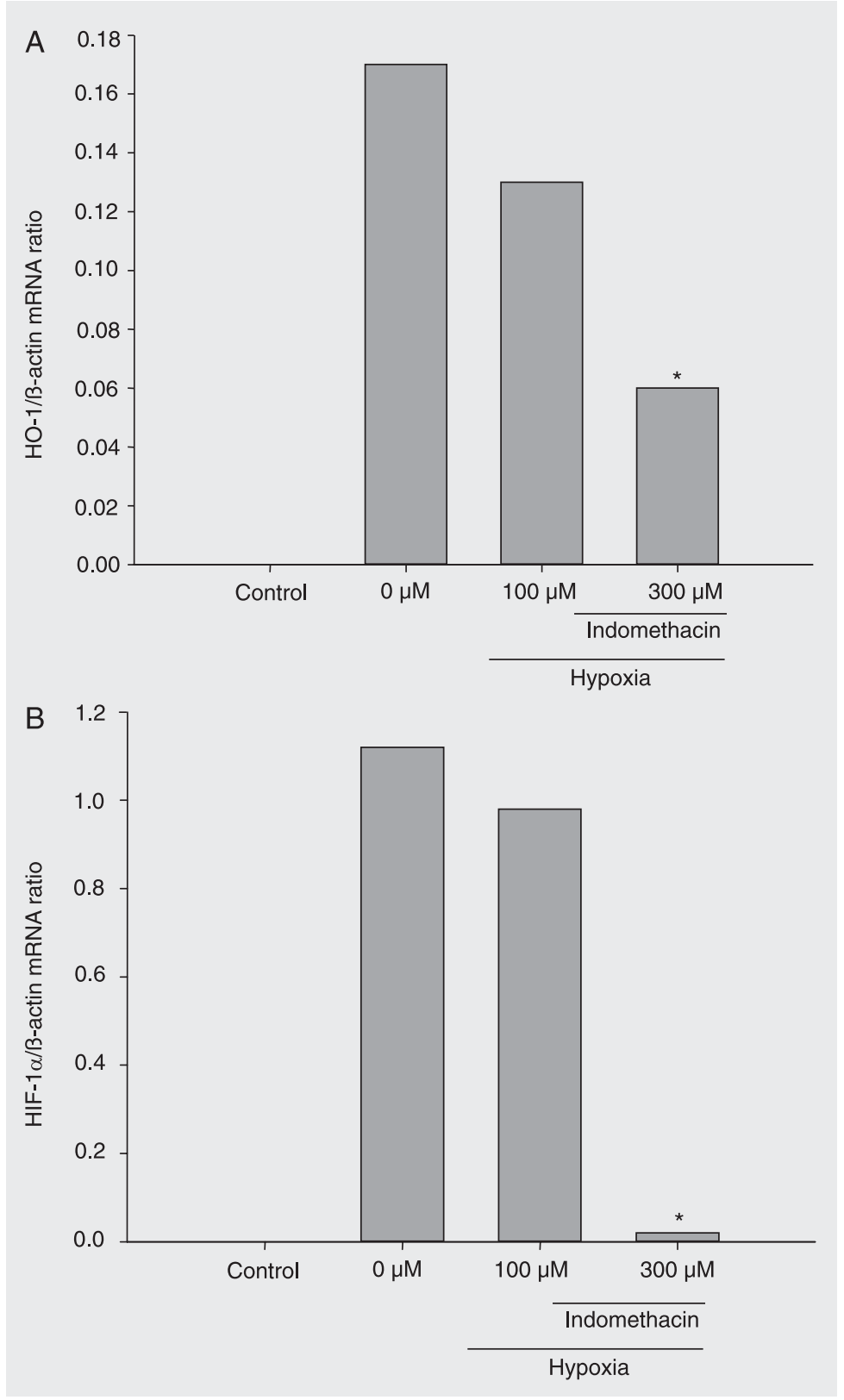

Figure 4. HO-1 (panel A) and HIF-1 $\alpha$ (panel B) mRNA expressed by control endothelial cells, by endothelial cells subjected to hypoxia and by cells pre-treated with 100 and $300 \mu \mathrm{M}$ indomethacin and subjected to hypoxia. Gene transcripts were normalized to $\beta$-actin. $\mathrm{HO}-1$ = heme oxygenase-1; HIF-1 $\alpha=$ hypoxia-inducible factor- $1 \alpha$. Data are reported as the median of 8 independent experiments. ${ }^{*} P<0.05$ compared to respective hypoxia (Mann-Whitney U-test). kocytes, driving them into the tissue. Important mediators of this cascade are the ROS, which are produced during ischemia and released after reperfusion, due in part to the cleavage of arachidonic acid by COX-1 and COX-2 $(8,19,20)$. Although COX-2 is also expressed in response to several physiological stimuli, it is the key molecule in inflammation. COX-2 up-regulation is a hallmark of IRI $(10,12)$. Moreover, many investigators have demonstrated the importance of the blockade of the COX pathway in promoting better organ function in ischemic injuries. Indeed, we have demonstrated that animals treated with indomethacin were protected against IRI in a mouse model of acute renal failure $(11,12)$.

When the endothelium is facing an insult, this barrier is able to orchestrate a protective cellular response that ultimately involves the inducible expression of genes with anti-inflammatory and anti-apoptotic properties, such as bcl-2 and HO-1. Thus, the balance between aggression and intrinsic cytoprotection ultimately determines the outcome of the injured tissue or organ.

Here, we describe in an in vitro model that the inhibition of COX-1 and COX-2 mRNA expression by a specific, although non-selective drug, improved endothelial cell function after gaseous hypoxia. Indomethacin treatment was associated with an enhancement of endothelial cell viability concurrent with COX mRNA inhibition. Indeed, we observed that once the noxious stimuli presented by the COXs were prevented, the expression of HO-1 was also largely inhibited. Additionally, we observed that indomethacin positively down-regulated the mRNA of the transcriptional factor HIF- $1 \alpha$ and the RANTES chemokines.

Recent data suggest that endothelial cells are highly specialized in acquiring a protective phenotype when facing a stressor. The role of the so-called "protective genes" has been well documented in recent years. Specifically, HO-1 represents one of the best 
examples of this gene family. HO-1 acts as an anti-apoptotic, an anti-inflammatory and an anti-proliferative molecule through its end products carbon monoxide, biliverdin and free iron (21). Its role in promoting better organ function has been demonstrated in different animal and human models $(22,23)$.

Interestingly, the relationship between HO- 1 and COX is just being clarified. Prior up-regulation of HO-1 in endothelial cells has been associated with protection against apoptosis and cellular dysfunction (24-26). However, once the insult is established, cellular protection can also be achieved by limiting COX-2 production via specific drug inhibitors. The influence of COX-2 on the suppression or enhancement of HO-1 expression is of considerable physiological importance.

HO-1 is up-regulated following IRI and endotoxemia (20). In these models, COX-2 is also up-regulated. Indeed, Ejima and Perrella (27) demonstrated that in the absence of COX-2 there is no up-regulation of HO-1 following LPS treatment in mice, demonstrating that $\mathrm{COX}$ is actually the stimulus for $\mathrm{HO}-1$ expression. In contrast, but in agreement with these data, prior induction of HO1 by gene therapy or by chemical products, such as cobalt protoporphyrin, abrogates COX-2 expression in various inflammatory models (28-30). Similarly, treatment with a COX-2 inhibitor is associated with HO-1 up-regulation (31). Furthermore, it has been reported that arachidonic acid, a substrate of COX, induces HO-1 activity (32), although the mechanism is not totally clear. Finally, few recent data incriminated ROS production, induced by $\mathrm{COX}$, in promoting $\mathrm{HO}-1$ expression (33). In this respect, COX inhibition is in fact associated with HO-1 repression, making this relationship controversial.

In the present study, we showed that COX inhibition was indeed followed by an improvement in cell integrity and a less proinflammatory phenotype, taking into account the repression of RANTES mRNA. We believed that, once we had prevented the potential harm embodied by those molecules, HO-1 was not induced, as the danger signal was no longer present. Data from Takeda and colleagues (33) agree with our results. Following glucose deprivation, cardiac fibroblasts up-regulated HO-1 and COX-2, which were then inhibited by $\mathrm{N}$-acetylcysteine (33).

We showed that HO-1 was induced by hypoxic stress and that its expression was negatively regulated by blockade of the COX pathway. The beneficial effect of indomethacin seems to involve down-modulation of chemokine production. The possibility of limiting the inflammatory cascade that follows IRI has new implications for those patients at high risk of ischemic events. Early inhibition of the COX pathway is demonstrated to be a useful tool in improving organ function after ischemic damage.

\section{References}

1. Thadhani R, Pascual M, Bonventre JV. Acute renal failure. N Engl J Med 1996; 334: 1448-1460.

2. Perico N, Cattaneo D, Sayegh MH, Remuzzi G. Delayed graft function in kidney transplantation. Lancet 2004; 364: 1814-1827.

3. Ojo AO, Wolfe RA, Held PJ, Port FK, Schmouder RL. Delayed graft function: risk factors and implications for renal allograft survival. Transplantation 1997; 63: 968-974.

4. Takada M, Chandraker A, Nadeau KC, Sayegh MH, Tilney NL. The role of the B7 costimulatory pathway in experimental cold ischemia/ reperfusion injury. J Clin Invest 1997; 100: 1199-1203.

5. Berna N, Arnould T, Remacle J, Michiels C. Hypoxia-induced in- crease in intracellular calcium concentration in endothelial cells: role of the $\mathrm{Na}(+)$-glucose cotransporter. J Cell Biochem 2001; 84: 115131.

6. Kawai T, Seki M, Hiromatsu K, Eastcott JW, Watts GF, Sugai M, et al. Selective diapedesis of Th1 cells induced by endothelial cell RANTES. J Immunol 1999; 163: 3269-3278.

7. Taub DD, Conlon K, Lloyd AR, Oppenheim JJ, Kelvin DJ. Preferential migration of activated CD4+ and CD8+ T cells in response to MIP-1 alpha and MIP-1 beta. Science 1993; 260: 355-358.

8. DeWitt DL. Prostaglandin endoperoxide synthase: regulation of enzyme expression. Biochim Biophys Acta 1991; 1083: 121-134. 
9. Wei Z, Costa K, Al-Mehdi AB, Dodia C, Muzykantov V, Fisher AB. Simulated ischemia in flow-adapted endothelial cells leads to generation of reactive oxygen species and cell signaling. Circ Res 1999; 85: 682-689.

10. Domoki F, Veltkamp R, Thrikawala N, Robins G, Bari F, Louis TM, et al. Ischemia-reperfusion rapidly increases COX-2 expression in piglet cerebral arteries. Am J Physiol 1999; 277: H1207-H1214.

11. Feitoza CQ, Sanders H, Cenedeze M, Camara NO, Pacheco-Silva A. Pretreatment with indomethacin protects from acute renal failure following ischemia-reperfusion injury. Transplant Proc 2002; 34: 2979-2980.

12. Feitoza CQ, Camara NO, Pinheiro HS, Goncalves GM, Cenedeze MA, Pacheco-Silva A, et al. Cyclooxygenase 1 and/or 2 blockade ameliorates the renal tissue damage triggered by ischemia and reperfusion injury. Int Immunopharmacol 2005; 5: 79-84.

13. Camara NO, Soares MP. Heme oxygenase-1 (HO-1), a protective gene that prevents chronic graft dysfunction. Free Radic Biol Med 2005; 38: 426-435.

14. Lee JW, Bae SH, Jeong JW, Kim SH, Kim KW. Hypoxia-inducible factor (HIF-1)alpha: its protein stability and biological functions. Exp Mol Med 2004; 36: 1-12.

15. Zagorska A, Dulak J. HIF-1: the knowns and unknowns of hypoxia sensing. Acta Biochim Pol 2004; 51: 563-585.

16. Mazure NM, Brahimi-Horn MC, Berta MA, Benizri E, Bilton RL, Dayan F, et al. HIF-1: master and commander of the hypoxic world. A pharmacological approach to its regulation by siRNAs. Biochem Pharmacol 2004; 68: 971-980.

17. de Souza Durao M Jr, Razvickas CV, Goncalves EA, Okano IR, Camargo SM, Monte JC, et al. The role of growth factors on renal tubular cells submitted to hypoxia and deprived of glucose. Ren Fail 2003; 25: 341-353.

18. Bonnekoh B, Farkas B, Geisel J, Mahrle G. Lactate dehydrogenase release as an indicator of dithranol-induced membrane injury in cultured human keratinocytes. A time profile study. Arch Dermatol Res 1990; 282: 325-329.

19. Simon LS. Role and regulation of cyclooxygenase-2 during inflammation. Am J Med 1999; 106: 37S-42S.

20. Kim SH, Lee SM. Expression of hepatic vascular stress genes following ischemia/reperfusion and subsequent endotoxemia. Arch Pharm Res 2004; 27: 769-775.

21. Otterbein LE, Soares MP, Yamashita K, Bach FH. Heme oxygenase-1: unleashing the protective properties of heme. Trends Immunol 2003; 24: 449-455.

22. Otterbein LE, Zuckerbraun BS, Haga M, Liu F, Song R, Usheva A, et al. Carbon monoxide suppresses arteriosclerotic lesions associated with chronic graft rejection and with balloon injury. Nat Med 2003; 9: 183-190.

23. Yamashita K, McDaid J, Ollinger R, Tsui TY, Berberat PO, Usheva $A$, et al. Biliverdin, a natural product of heme catabolism, induces tolerance to cardiac allografts. FASEB J 2004; 18: 765-767.

24. Parfenova H, Neff RA III, Alonso JS, Shlopov BV, Jamal CN, Sarkisova SA, et al. Cerebral vascular endothelial heme oxygenase: expression, localization, and activation by glutamate. Am J Physiol Cell Physiol 2001; 281: C1954-C1963.

25. Quan S, Yang L, Shnouda S, Jiang H, Balazy M, Schwartzman ML, et al. Functional expression of human heme oxygenase-1 (HO-1) driven by HO-1 promoter in vitro and in vivo. J Cell Biochem 2002 ; 85: 410-421.

26. Haider A, Olszanecki R, Gryglewski R, Schwartzman ML, Lianos E, Kappas A, et al. Regulation of cyclooxygenase by the heme-heme oxygenase system in microvessel endothelial cells. J Pharmacol Exp Ther 2002; 300: 188-194.

27. Ejima K, Perrella MA. Alteration in heme oxygenase-1 and nitric oxide synthase-2 gene expression during endotoxemia in cyclooxygenase-2-deficient mice. Antioxid Redox Signal 2004; 6: 850-857.

28. Quan S, Yang L, Shnouda S, Schwartzman ML, Nasjletti A, Goodman Al, et al. Expression of human heme oxygenase-1 in the thick ascending limb attenuates angiotensin II-mediated increase in oxidative injury. Kidney Int 2004; 65: 1628-1639.

29. Vicente AM, Guillin MI, Alcaraz MJ. Participation of heme oxygenase-1 in a model of acute inflammation. Exp Biol Med 2003; 228 : 514-516.

30. Li Volti G, Seta F, Schwartzman ML, Nasjletti A, Abraham NG. Heme oxygenase attenuates angiotensin II-mediated increase in cyclooxygenase-2 activity in human femoral endothelial cells. $\mathrm{Hy}$ pertension 2003; 41: 715-719.

31. Fernandez P, Guillen MI, Gomar F, Aller E, Molina P, Alcaraz MJ. A novel cyclo-oxygenase-2 inhibitor modulates catabolic and antiinflammatory mediators in osteoarthritis. Biochem Pharmacol 2004; 68: 417-421.

32. Andoh Y, Suzuki H, Araki M, Mizutani A, Ohashi T, Okumura T, et al. Low- and high-level expressions of heme oxygenase-1 in cultured cells under uninduced conditions. Biochem Biophys Res Commun 2004; 320: 722-729.

33. Takeda K, Lin J, Okubo S, Kazawa-Kudoh S, Kajinami K, Kanemitsu $\mathrm{S}$, et al. Transient glucose deprivation causes upregulation of heme oxygenase-1 and cyclooxygenase-2 expression in cardiac fibroblasts. J Mol Cell Cardiol 2004; 36: 821-830. 